\section{(2) OPEN ACCESS}

\title{
Trajectories of material living standards, physical health and mental health under a universal pension
}

\author{
Joanne Allen 두, Fiona M Alpass
}

\begin{abstract}
- Additional material is published online only. To view please visit the journal online (http://dx.doi.org/10.1136/ jech-2019-213199).
\end{abstract}

School of Psychology, Massey University, Palmerston North, New Zealand

Correspondence to Dr Joanne Allen, School of Psychology, Massey University, Palmerston North 4442, New Zealand; j.allen@massey.ac.nz

Received 5 September 2019 Revised 20 December 2019 Accepted 28 December 2019 Published Online First 15 January 2020

\section{Check for updates}

(C) Author(s) (or their employer(s)) 2020. Re-use permitted under CC BY-NC. No commercial re-use. See rights and permissions. Published by BMJ.

To cite: Allen J, Alpass FM. J Epidemiol Community Health 2020:74:362-368.

\begin{abstract}
Objective Aged pension schemes aim to support material and non-material well-being of older populations. The current work aimed to describe dominant trajectories of material living standards in the decades prior to and following eligibility for an aged pension, and describe associated trajectories of physical and mental health.

Methods Longitudinal data on living standards and indices of health Short Form 12 were collected over 2-12 years follow-up from 4811 New Zealand adults aged 55-76. Growth mixture models were used to identify dominant trajectories of living standards with age. Latent growth curve models were used to describe trajectories of physical and mental health associated with each living standards trajectory class.

Results A group characterised by good living standards with age $(81.5 \%)$ displayed physical and mental health scores comparable to those of the general adult population. Smaller groups experienced hardship but

life expectancy are well recognised. ${ }^{25}{ }^{6}$ However, increasing life expectancies and ageing populations have prompted several countries to review age criteria for pension eligibility ${ }^{11}$ and are predicated on an ability of older adults to sustain health and material well-being into later ages (eg, via paid employment or accumulated assets). Inequalities in material wealth and health states with which adults reach pensionable age mean that income support will have distinct impacts on living standards within the population. Understanding socioeconomic inequalities and their associations with health in later life is vital for informed evaluation of later life health and retirement income polices. Methods which acknowledge the presence of subpopulations who may have distinct experiences of material and non-material well-being within the general population present a powerful tool in understanding this diversity of experience, its determinants and correlates.
\end{abstract} increasing living standards (11.8\%) and hardship and declining living standards (6.8\%). While both groups in hardship experienced poor health in the decade prior pension eligibility, mental health improved among those with increasing living standards, while physical and mental health declined among those with declining living standards.

Conclusion Under the current policy settings, a majority of older adults in New Zealand maintain a good level of living standards and health in later life. However, significant proportions experience material hardship and poor health in the decade prior to pension eligibility. Alleviation of material hardship may reduce health inequalities in later life.

\section{BACKGROUND}

Socioeconomic inequalities in later life physical health, ${ }^{12}$ mental health ${ }^{34}$ and mortality ${ }^{56}$ are well established. These associations are understood to reflect reciprocal and cumulative impacts of health and socioeconomic advantage and disadvantage across the life course. ${ }^{7}$ While research continues into the influence of changes in income and associated living standards on health outcomes, ${ }^{8-10}$ there is relatively little understanding of changes in income and living standards and health among older adults.

Social polices supporting income and living conditions of older adults recognise that older age may present challengesfor individuals in maintaining levels of well-being valued by society. The potential for retirement income polices to influence socioeconomic inequalities in health and

\section{New Zealand context}

National surveys using non-income measures of material wealth suggest that older adults in New Zealand are a materially advantaged group relative to younger age cohorts. ${ }^{12}$ While around $16 \%$ of adults aged 45-64 report experiences of material hardship, this is reduced to $7 \%$ among those aged $65+,{ }^{12} 13$ in part attributed to eligibility for a universal public aged pension scheme at age 65 for adults who meet minimum residency criteria. The single-person pension rate is around $40 \%$ of the average wage, reviewed annually and adjusted for inflation and represents a key source of income for residents aged $65+,{ }^{14}$ with only $12 \%$ of adults aged $65+$ deriving income from other pension schemes. ${ }^{15}$ These polices have been highly stable in recent decades, with age of eligibility last raised incrementally from 61 to 65 between 1992 and 2001.

\section{Aims and objectives}

The current work will describe trajectories of material living standards among New Zealand adults in the decades prior to and following eligibility for a public aged pension. A growth mixture modelling approach is adopted to identify subpopulations displaying distinct levels and changes in living standards with age. To assess the association of these living standards trajectories with health outcomes, we describe concurrent trajectories of physical and mental health associated with these living standards profiles. 


\section{METHODS}

\section{Study design}

Data were collected in nine waves of the Health, Work and Retirement longitudinal study conducted during 2006-2018. ${ }^{16}$ Participants were recruited from random samples drawn from the New Zealand electoral roll in 2006, 2009, 2010, 2014 and 2016. Oversampling of persons of Māori descent was undertaken to ensure adequate representation of the older Māori population. Sampled adults were sent a postal survey assessing living standards, health and demographic characteristics. Description of recruitment waves by age and birth cohort are described in online supplementary file 1 .

\section{Participants and inclusion criteria}

Participants were included in the current analyses if they provided information on living standards in at least two surveys between ages 55 and 76 . Of the 10574 adults who responded to the study between 2006 and 2016, 9844 were observed at least once between the ages of 55 and 74 . Of these, 4909 responded to two or more surveys between ages 55 and 76 (surveys 20062018) and 4811 provided adequate data on living standards at least twice during this period.

\section{Variables}

Age, gender, ethnicity, highest level of education and marital status were assessed at each survey wave. Participant marital status was highly stable over the observation period with $92.4 \%$ displaying no change in relationship status, with $5.5 \%$ indicating that they experienced a relationship loss $(3.0 \%$ widowed, $2.5 \%$ divorced). Where change was observed, the most frequent marital status for an individual was used, else status at first observation was used. Participant mortality outcome between ages 55 and 76 during the follow-up period was derived from linkage to national mortality records at 14 May 2019 (99.4\% match rate).

Material living standards were assessed using the Economic Living Standards Index Short Form (ELSI-SF), a 25 -item nonincome measure of material well-being. ${ }^{17}$ Such non-income-based measures are particularly appropriate for assessing material wellbeing of older adults, whose primary income may be an aged pension, regardless of accumulated material resources. Scores range from 0 to 31 with higher scores indicating better living standards. Scores are categorised as indicative of 'very good' (31-29), 'good' (28-25), 'comfortable' (24-21), 'fairly comfortable' (20-17), 'some hardship' (16-13), 'significant hardship' (12-9) or 'severe hardship' (8-0) living standards, with the lowest three categories considered to indicate material hardship. ${ }^{17} 18$

Physical and mental health were assessed using items of the SF-12 Australian and New Zealand form. ${ }^{19}$ Standardised total scores for the physical and mental health components were calculated with reference to normative subscale scores and factor coefficients for the New Zealand population ${ }^{20}$ and are interpreted relative to an average adult population score of 50 and an SD of 10.

\section{Analysis plan}

Mplus V.8.3 ${ }^{21}$ was used for all growth and regression analyses. SPSS V.25.0 was used to generate descriptive statistics. Item-level data were imputed within survey waves using the SPSS in-built expectation maximisation algorithm for the ELSI-SF where less than five items were missing, and with reference to guidelines for missing data imputation for the SF-12. Less than $1 \%$ of item data for any scale was imputed for any survey wave. Data were weighted for response characteristics with reference to age, gender, Māori decent and area-level socioeconomic deprivation $^{22}$ of original random samples.

Longitudinal data were restructured into eleven 2-year age brackets to represent increments in age for all growth models. Growth mixture models of change in living standards with age were estimated and the optimal number of classes was determined with reference to class size, class interpretability, Entropy and Average Posterior Probabilities of class separation and samplesize-adjusted Bayesian information criterion, and the samplesize-adjusted Lo-Mendell-Rubin likelihood ratio test assessing improvement in model fit between $\mathrm{k}$ and $\mathrm{k}-1$ classes. ${ }^{23} 24$ Entropy values of $0.40,0.60$ and 0.80 were considered to represent low, medium and high class separation. ${ }^{25}$ Model intercepts were specified to describe participants at age 63-64 (prior to pension eligibility). Class proportions additionally weighted to account for oversampling design were reported to evaluate class proportions with reference to the general adult population. The associations of living standards class membership with demographic factors were assessed using the Mplus AUXILLARY R3STEP multinomial logistic regression procedure. ${ }^{26}$ Latent growth curve models of physical and mental health with age were estimated to assess concurrent health trajectories associated with living standards class membership. Assessments of risks to inference associated with period and cohort effects are presented in online supplementary file 1.

\section{RESULTS}

\section{Participants}

On average, participants provided information on their living standards within $3.9(\mathrm{SD}=1.9)$ age brackets. Inspection of average ELSI-SF scores over observations indicates that a majority reported living standards categorised as very good $(18.6 \%)$ or good $(35.0 \%)$, with smaller proportions having scores regarded as representing comfortable (20.3\%), fairly comfortable (11.3\%), some hardship (6.9\%), significant hardship (3.9\%) or severe hardship (4.0\%). Demographic characteristics for the overall sample are reported in table 1 .

\section{Dominant trajectories of living standards with age}

Growth mixture models specifying two, three and four latent classes were estimated and indices of model fit and class membership presented in table 2 . Information criteria statistics improved with the number of classes estimated, and class separation was high for all models. Comparison of the range of average posterior probabilities associated with class membership indicated a two-class model displayed high class separation, with declines in certainty around class membership observed for the threeclass and four-class models. Likelihood ratio tests indicated that the two-class model displayed significantly better fit to the data than the overall (one-class) model, and the three-class model displayed better fit than the two-class model. The four-class model provided a small improvement to model fit, identifying two small classes.

Design-weighted class proportions and model estimates for the two-, three-, and four-class models are presented in table 3. The two-class model characterised two subpopulations with distinct combinations of levels and changes in living standards with age. The largest group $\left(\mathrm{C}_{1}\right)$ were characterised by mean scores indicative of good living standards at age 63-64, which remained stable with age. The second group $\left(\mathrm{C} 22_{2}\right)$ were characterised by mean scores indicative of significant hardship at age 63-64, which improved with age. For this group, each one-step 
Table 1 Demographic characteristics of the sample overall and by living standards (LS) trajectory class with adjusted odds of class membership from multinomial logistic regression $(n=4811)$

\begin{tabular}{|c|c|c|c|c|c|c|c|}
\hline & Sample & $\begin{array}{l}\left(\mathrm{C} 3_{1}\right) \\
\text { Good LS }\end{array}$ & $\begin{array}{l}\left(\mathrm{C} 3_{2}\right) \\
\text { Hardship, } \uparrow \text { LS }\end{array}$ & $\begin{array}{l}\left(\mathrm{C}_{3}\right) \\
\text { Hardship, } \downarrow \text { LS }\end{array}$ & $\begin{array}{l}\text { AOR }(95 \% \mathrm{Cl}) \\
\mathrm{C3}_{2} \text { vs C3 } 1 \text { (ref) }\end{array}$ & $\begin{array}{l}\text { AOR }(95 \% \mathrm{Cl}) \\
\mathrm{C3}_{3} \text { vs } \mathrm{C3}_{1 \text { (ref) }}\end{array}$ & $\begin{array}{l}\text { AOR }(95 \% \mathrm{Cl}) \\
\mathrm{C3}_{3} \text { vs } \mathrm{C3}_{2 \text { (ref) }}\end{array}$ \\
\hline Age (mean, SD) $\dagger$ & $63.6(4.6)$ & $63.6(4.7)$ & $63.4(4.7)$ & $63.6(4.5)$ & $1.0(0.9 \text { to } 1.0)^{* *}$ & $1.0(1.0$ to 1.0$)$ & $1.0(1.0$ to 1.1$)$ \\
\hline \% Māori & 46.7 & 43.0 & 62.8 & 63.5 & $2.0(1.6 \text { to } 2.6)^{* * *}$ & $2.2(1.7 \text { to } 3.0)^{* *}$ & $1.1(0.7$ to 1.7$)$ \\
\hline$\%$ female & 52.3 & 50.9 & 57.9 & 59.2 & 1.1 (0.9 to 1.5$)$ & $1.2(0.9$ to 1.7$)$ & 1.1 (0.7 to 1.6$)$ \\
\hline$\%$ not married or de facto & 26.8 & 21.1 & 53.1 & 50.8 & $5.0(3.9 \text { to } 6.5)^{* * *}$ & $4.1(3.0 \text { to } 5.5)^{* * *}$ & $0.8(0.5$ to 1.3$)$ \\
\hline$\%$ no tertiary qualification & 80.5 & 78.5 & 90.3 & 87.6 & $2.9(1.8 . \text { to } 4.5)^{*}$ & 1.7 (1.1 to 2.6$)$ & $0.6(0.3$ to 1.2$)$ \\
\hline$\%$ deceased & 8.6 & 7.3 & 15.9 & 12.1 & $2.2(1.6 \text { to } 3.1)^{* *}$ & $1.4(0.8$ to 2.2$)$ & $0.6(0.3$ to 1.3$)$ \\
\hline
\end{tabular}

Data weighted by response characteristics; marital status missing $n=2$; qualification missing $n=3$.

${ }^{*} \mathrm{P}<0.05,{ }^{*} \mathrm{P}<0.01,{ }^{*}{ }^{*} \mathrm{P}<0.001$

tAverage age over observations.

$\uparrow$, increase with age; $\downarrow$, decrease with age; AOR, adjusted OR; LS, living standards; ref, reference class for comparison.

increment in age bracket was associated with an average 0.8point increase in ELSI-SF score.

In the three-class model, estimates for the largest group ( $\left.\mathrm{C} 3_{1}\right)$ remained consistent with those observed in the two-class model. The second group $\left(\mathrm{C}_{2}\right)$ were characterised by scores indicating some hardship at age 63-64, and an average 1.6-point increase in ELSI-SF score with each increment in age bracket. Observed average living standards were no longer indicative of hardship at ages 67-68. The third group $\left(\mathrm{C} 3_{3}\right)$ indicated the emergence of a small subpopulation characterised by some-significant hardship at age 63-64, and an average - 0.8-point decline in ELSI-SF score with each increment in age bracket. Observations of average scores by age bracket, indicate living standards decline to ages 63-64, with estimates indicating significant hardship continuing throughout the observation period.

Estimates of the four-class model were largely consistent with those represented in the three-class model, with the emergence of a very small class in severe hardship (representing 3.4\%

Table 2 Growth mixture model fit statistics, class sizes indicating the optimal number of classes representing diversity in living standards trajectories with age $(n=4811)$

\begin{tabular}{|c|c|c|c|}
\hline Fit statistics & $\begin{array}{l}\text { Two-class model } \\
\text { (C2) }\end{array}$ & $\begin{array}{l}\text { Three-class model } \\
\text { (C3) }\end{array}$ & $\begin{array}{l}\text { Four-class model } \\
\text { (C4) }\end{array}$ \\
\hline Log-likelihood value & -52790.4 & -52573.9 & -52425.0 \\
\hline $\begin{array}{l}\text { No estimated } \\
\text { parameters }\end{array}$ & 19 & 22 & 25 \\
\hline \multicolumn{4}{|l|}{ Information criteria } \\
\hline SSABIC & 105681.5 & 105264.5 & 104982.5 \\
\hline \multicolumn{4}{|l|}{ Class reliability } \\
\hline Entropy & 0.85 & 0.84 & 0.82 \\
\hline $\begin{array}{l}\text { Av. posterior } \\
\text { probabilities } \\
\text { range }\end{array}$ & $0.90-0.97$ & $0.78-0.96$ & $0.72-0.94$ \\
\hline \multicolumn{4}{|l|}{ k versus k-1 classes } \\
\hline $\begin{array}{l}\text { Adj. LMR-LRT ( } p \\
\text { value) }\end{array}$ & $1193.1(0.000)$ & $416.6(0.000)$ & $286.6(0.022)$ \\
\hline \multicolumn{4}{|l|}{ Class size (sample \%) } \\
\hline$C_{1}$ & 3997 (83.1) & 3920 (81.5) & $3577(74.4)$ \\
\hline $\mathrm{C}_{2}$ & $814(16.9)$ & $566(11.8)$ & $652(13.6)$ \\
\hline $\mathrm{C}_{3}$ & & $326(6.8)$ & $323(6.7)$ \\
\hline $\mathrm{C}_{4}$ & & & $259(5.4)$ \\
\hline
\end{tabular}

Data weighted by response characteristics.

Adj.LMR-LRT, Adjusted Lo-Mendell-Rubin likelihood ratio test; SSABIC, Sample-size

adjusted Bayesian information criteria. design-weighted responses). Due to the limited potential for this profile to provide additional information, and its small class sizes, this model was not considered further.

In light of the substantial variations in living standards with age displayed by classes in the three-class solution, this was retained as the optimal model to represent dominant trajectories of living standards with age in the current data. Figure 1 illustrates the mean observed and estimated trajectory of living standards with age by class for the three-class model (C3). Patterns of living standards with age by class were inspected for each ELSI-SF subscale, and presented in online supplementary file 2 .

\section{Demographic correlates of living standards}

Demographic characteristics for each living standards class, and adjusted odds of class membership, are presented in table 1 . Compared with the group characterised by good living $\left(\mathrm{C} 3_{1}\right)$ standards, increased odds of belonging to a profile characterised by hardship prior to pension eligibility $\left(\mathrm{C}_{2}\right.$ or $\left.\mathrm{C} 3_{3}\right)$ were associated with Māori decent, and not being in a married or de facto relationship. Those characterised by hardship but increasing living standards with age $\left(\mathrm{C} 3_{2}\right)$ were additionally more likely to have no tertiary education and were more likely to be deceased during the follow-up period compared with those with good living standards. There were no differences in demographic characteristics between groups characterised by hardship prior to pension eligibility ( $\mathrm{C} 3_{2}$ and $\left.\mathrm{C} 3_{3}\right)$.

\section{Trajectories of health with age by living standards profile}

Estimated coefficients for the linear models of physical and mental health with age by living standards profile are displayed in table 4. Line graphs depicting observed mean and 95\% CIs for physical and mental health scores with age by living standards profile are presented in online supplementary file 3 .

On average the group characterised by good living standards $\left(\mathrm{C} 3_{1}\right)$ displayed physical health scores at age 63-64 that were within half a SD of the adult population mean. Physical health declined with age, with each one-step increment in age bracket associated with an average 0.7 -point decline in physical health score. A positive covariation of the intercept and slope indicated that those in better health at age 63-64 displayed a faster decline in physical health with age. Groups characterised by hardship prior to pension eligibility $\left(\mathrm{C} 3_{2}\right.$ and $\left.\mathrm{C} 3_{3}\right)$ on average displayed a level of physical health at age 63-64 approximately $1 \mathrm{SD}$ below the population mean. While the group characterised by increasing living standards $\left(\mathrm{C}_{2}\right)$ reported no change in physical health over time, those characterised by decreasing living 
Table 3 Mean $(95 \% \mathrm{Cl})$ growth parameters for two-, three-, and four-class growth mixture models of living standards (LS) trajectories with age

\begin{tabular}{|c|c|c|c|c|c|c|c|}
\hline & \multirow{2}{*}{$\begin{array}{l}\text { Est. population } \\
\% \dagger\end{array}$} & \multicolumn{2}{|l|}{ Intercept (I) } & \multicolumn{2}{|l|}{ Linear slope (S) } & \multirow{2}{*}{$\begin{array}{l}\text { Factor covariance }(\mathrm{I}-\mathrm{S}) \mp \\
\text { Mean }(95 \% \mathrm{CI})\end{array}$} & \multirow[b]{2}{*}{ Description } \\
\hline & & Mean $(95 \% \mathrm{Cl})$ & Variance $\ddagger$ & Mean $(95 \% \mathrm{Cl})$ & Variance $\ddagger$ & & \\
\hline \multicolumn{8}{|c|}{ Two-class model } \\
\hline $\mathrm{C}_{1}$ & 87.4 & $25.4(25.3 \text { to } 25.6)^{* * *}$ & $11.8^{* * *}$ & $0.1(0.1$ to 0.2$) * * *$ & $0.3^{* * *}$ & $0.2(-0.1$ to 0.5$)$ & Good LS \\
\hline $\mathrm{Cl}_{2}$ & 12.6 & $12.4(11.8 \text { to } 13.0)^{* * *}$ & $11.8^{* * *}$ & $0.8(0.6 \text { to } 1.0)^{* * *}$ & $0.3^{* * *}$ & $0.2(-0.1$ to 0.5$)$ & Hardship, $\uparrow$ LS \\
\hline \multicolumn{8}{|c|}{ Three-class model (optimal model) } \\
\hline $\mathrm{C}_{1}$ & 86.1 & $25.6(25.4 \text { to } 25.7)^{* * *}$ & $11.2^{* * *}$ & $0.1(0.1 \text { to } 0.2)^{* * *}$ & $0.1^{* * *}$ & $-0.1(-0.2$ to 0.0$)$ & Good LS \\
\hline $\mathrm{C}_{2}$ & 8.8 & $13.4(12.6 \text { to } 14.2)^{* * *}$ & $11.2^{* * *}$ & $1.6(1.4 \text { to } 1.7)^{* * *}$ & $0.1^{* * *}$ & $-0.1(-0.2$ to 0.0$)$ & Hardship, $\uparrow$ LS \\
\hline $\mathrm{C}_{3}$ & 5.1 & $12.4(10.9 \text { to } 13.8)^{* * *}$ & $11.2^{* * *}$ & $-0.8(-1.1 \text { to }-0.5)^{* * *}$ & $0.1^{* * *}$ & $-0.1(-0.2$ to 0.0$)$ & Hardship, $\downarrow$ LS \\
\hline \multicolumn{8}{|c|}{ Four-class model } \\
\hline $\mathrm{C}_{1}$ & 80.2 & $26.2(26.0 \text { to } 26.4)^{* * *}$ & $6.6^{* * *}$ & $0.1(0.1 \text { to } 0.2)^{* * *}$ & $0.1 * * *$ & $-0.0(-0.2$ to 0.1$)$ & Good LS \\
\hline $\mathrm{C}_{2}$ & 10.8 & $16.4(15.5 \text { to } 17.4)^{* * *}$ & $6.6^{* * *}$ & $1.3(1.0 \text { to } 1.5)^{* * *}$ & $0.1^{* * *}$ & $-0.0(-0.2$ to 0.1$)$ & Hardship, $\uparrow \mathrm{LS}$ \\
\hline $\mathrm{C}_{3}$ & 5.6 & $17.2(15.9 \text { to } 18.5)^{* * *}$ & $6.6^{* * *}$ & $-0.7(-1.1 \text { to }-0.4)^{* * *}$ & $0.1^{* * *}$ & $-0.0(-0.2$ to 0.1$)$ & Comfortable, $\downarrow$ LS \\
\hline $\mathrm{C}_{4}$ & 3.4 & $6.7(5.9 \text { to } 7.4)^{* * *}$ & $6.6^{* * *}$ & $0.3(0.0$ to 0.7$)$ & $0.1^{* * *}$ & $-0.0(-0.2$ to 0.1$)$ & Hardship LS \\
\hline
\end{tabular}

Data weighted by response characteristics; model intercept represents mean ELSI-SF score ages 63-64.

${ }^{*} \mathrm{P}<0.05,{ }^{*} \mathrm{P}<0.01,{ }^{* *} \mathrm{P}<0.001$

†Design-weighted proportions.

¥Partially restricted growth mixture model with between-class invariant variances and covariance.

$\downarrow$, decrease with age; $\uparrow$, increase with age; ELSI-SF, Economic Living Standards Index Short Form; LS, living standards.

standards $\left(\mathrm{C}_{3}\right)$ reported an average 1.0-point decline in physical health with each increment in age bracket.

In terms of mental health, on average the group characterised by good living standards $\left(\mathrm{C} 3_{1}\right)$ displayed scores at age 63-64 comparable to the population mean, which remained stable with age. Those in groups characterised by hardship prior to pension eligibility $\left(\mathrm{C} 3_{2}\right.$ and $\left.\mathrm{C} 3_{3}\right)$ on average displayed mental health scores approximately 1 SD below the population mean at age 63-64. While those characterised by hardship but increasing living standards $\left(\mathrm{C}_{2}\right)$ reported an average 0.8 point increase in mental health score with each one-step increment in age bracket, those characterised by hardship and decreasing living standards $\left(\mathrm{C}_{3}\right)$ reported an average 0.4 -point decline in mental health with each increment in age bracket.

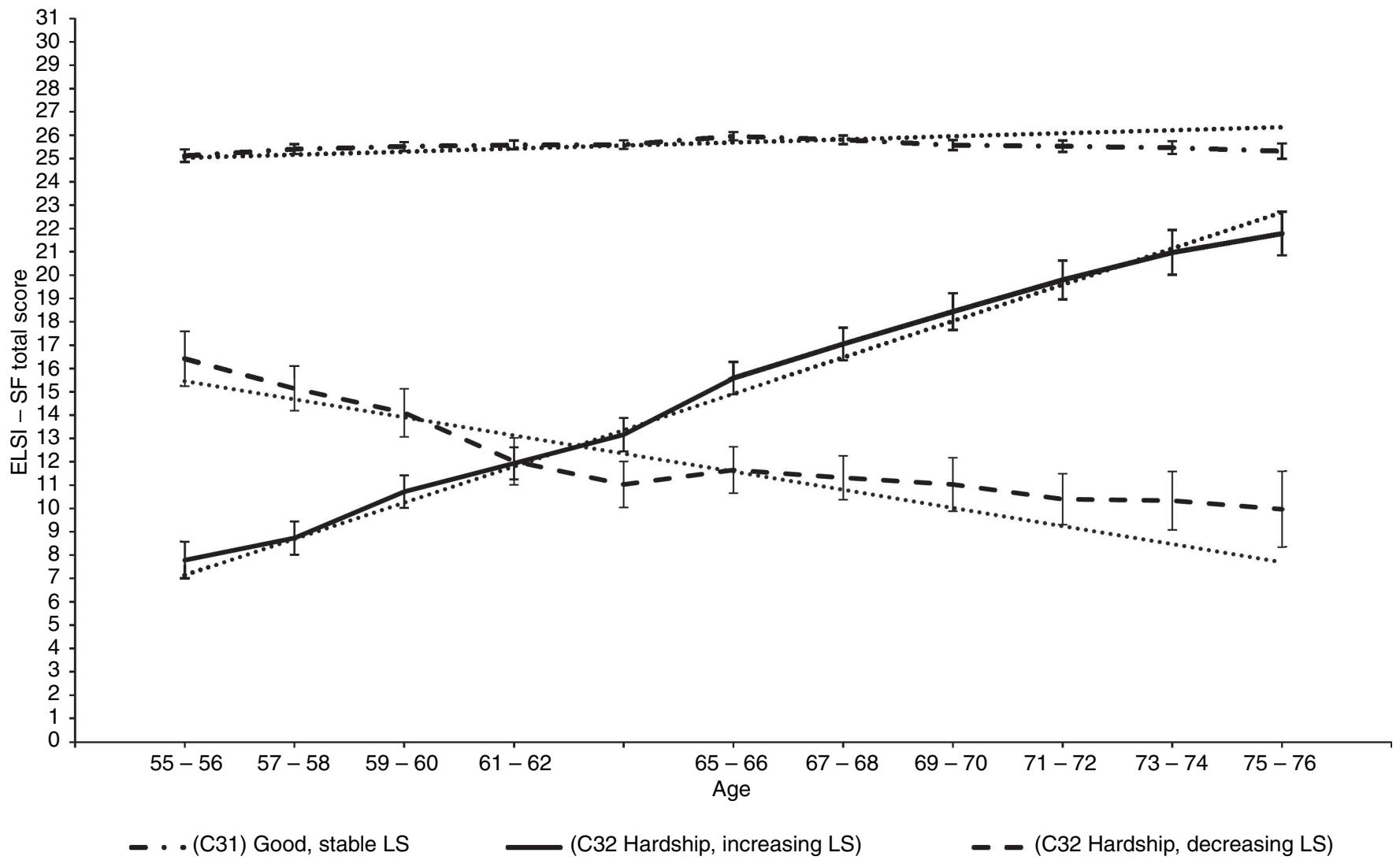

Figure 1 Mean and 95\% Cl for observed Economic Living Standards Index Short Form (ELSI-SF) score by age and living standards (LS) trajectory class. Dotted lines indicate estimated linear trajectories. 
Table 4 Mean $(95 \% \mathrm{Cl})$ coefficient estimates for linear model of physical and mental health with age by living standards (LS) trajectory class $(n=4806)$

\begin{tabular}{|c|c|c|c|c|c|}
\hline & \multicolumn{2}{|l|}{ Intercept (I) } & \multicolumn{2}{|l|}{ Linear slope (S) } & \multirow{2}{*}{$\begin{array}{l}\text { Factor covariance (I-S) } \\
\text { Mean }\end{array}$} \\
\hline & Mean & Variance & Mean & Variance & \\
\hline \multicolumn{6}{|l|}{ Physical health } \\
\hline$\left(\mathrm{C}_{1}\right)$ Good LS & $47.6(47.4 \text { to } 47.8)^{* * *}$ & $50.0 * * *$ & $-0.7(-0.7 \text { to }-0.6)^{* * *}$ & $0.8^{* * *}$ & $1.6(1.1 \text { to } 2.0)^{* * *}$ \\
\hline (C3 $\left.{ }_{2}\right)$ Hardship, $\uparrow$ LS & $38.8(38.0 \text { to } 39.6)^{* * *}$ & $85.5^{* * *}$ & $-0.1(-0.3$ to 0.0$)$ & $1.2^{* * *}$ & $-1.4(-2.9$ to 0.2$)$ \\
\hline (C3 $\left.{ }_{3}\right)$ Hardship, $\downarrow$ LS & $39.4(38.4 \text { to } 40.4)^{* * *}$ & $77.8^{* * *}$ & $-1.0(-1.2 \text { to }-0.7)^{* * *}$ & 0.4 & $1.4(-0.5$ to 3.4$)$ \\
\hline \multicolumn{6}{|l|}{ Mental health } \\
\hline$\left(C 3_{1}\right)$ Good LS & $50.8(50.6 \text { to } 51.0)^{* * *}$ & $38.7^{* * *}$ & $0.1(0.1 \text { to } 0.2)^{* *}$ & $0.5^{* * *}$ & $-0.1(-0.5$ to 0.4$)$ \\
\hline$\left(\mathrm{C}_{2}\right)$ Hardship, $\uparrow$ LS & $41.7(40.9 \text { to } 42.5)^{* * *}$ & $73.0^{* * *}$ & $0.8(0.6 \text { to } 1.0)^{* * *}$ & $1.0^{* *}$ & $-2.1(-4.0$ to -0.3$)$ \\
\hline (C3 $\left.3_{3}\right)$ Hardship, $\downarrow$ LS & $40.5(39.5 \text { to } 41.6)^{* * *}$ & $84.0 * * *$ & $-0.4(-0.6 \text { to }-0.1)^{* *}$ & 0.1 & $-0.3(-2.5$ to 1.9$)$ \\
\hline
\end{tabular}

${ }^{*} \mathrm{P}<0.05,{ }^{*} \mathrm{P}<0.01,{ }^{* *} \mathrm{P}<0.001$.

Data weighted by response characteristics; model intercept represents average ELSI-SF score at ages 63-64.

$\downarrow$, decrease with age; $\uparrow$, increase with age; ELSI-SF, Economic Living Standards Index Short Form; LS, living standards.

\section{DISCUSSION}

Results indicate three major trajectories of living standards as adults approach and pass the age of pension eligibility in New Zealand. A majority of adults were characterised by good living standards prior to pension eligibility, which were maintained with age. Around $8.8 \%$ were characterised by experiences of hardship, but improved living standards with age. A small proportion $(5.5 \%)$ were characterised by declining living standards prior to reaching age of pension eligibility, and continued hardship in later life. These subpopulations highlight inequity in living standards as experienced among the older the New Zealand population, and provide a model for the assessment of the demographic and health correlates of material hardship and its alleviation.

Experiences of hardship were associated with known drivers of socioeconomic inequalities, such as not being in a married or de facto relationship. Current results similarly highlight socioeconomic inequalities in health spanning mid-later life. While the group characterised by good and stable living standards displayed levels of physical and mental health close to the adult population mean in the decade prior to pension eligibility, those classes characterised by material hardship experienced poor physical and mental health at these ages.

Current findings illustrate a decline in physical health with age among those with good living standards, likely representing a combination of the high level of physical health with which this group reach older age, processes of normal bodily ageing and transitions into retirement. While those adults characterised by hardship and declining living standards also experienced declines in physical and mental health with age, those whose living standards increased displayed no further decline in physical health, and improved mental health with age. Current observations that poor physical health was associated with declines but not improvements in living standards are consistent with findings of trends of health with income in other settings. ${ }^{9}$ Improvements in mental health with age among older adults experiencing improved living standards may reflect positive impact of alleviation of material hardship. In addition to research illustrating a negative impact of financial hardship on mental health, ${ }^{8} 27$ this finding is in line with qualitative research New Zealand retirees indicating a sense of ontological security associated with receipt of the age pension for those who have experienced chronic financial stress. ${ }^{28}$ Future research assessing the reciprocal burdens of living standards, health and labour participation among those experiencing hardship may provide further insight into drivers of these inequalities which may not be evident when considering the broader population.

Current results confirm that socioeconomic inequalities in health among older adults are shaped long before pensionable age but suggest some (limited) capacity of universal pension system to reduce inequalities in health accumulated across the life course. Results highlight the low level of physical and mental health resources, prior to age of pension eligibility, associated with socioeconomic disadvantage. While financial security, poor physical health and poor mental health are consistent predictors of early retirement, ${ }^{729}$ current results indicate that those most compelled to remain in employment due to financial need may be those least able to maintain health related ability to work. Research is lacking on health-related workability among older adults in New Zealand, however, initiatives to enable workforce participation in later life must also consider skill sets, the availability of suitable employment, the ability to obtain employment and willingness of employers to employ older workers.

\section{Strengths and limitations}

Strengths of the current study include its random selection of participants from a representative sampling frame and substantial longitudinal follow-up of adults on established indicators of material living standards and health. Adults included in the analyses display distributions in living standards of mid-life and later life adults consistent with those of New Zealand population surveys, ${ }^{12-14}$ and indicate that data represent adults experiencing a spectrum of severe hardship to very good living standards in the community. The analytical approach acknowledges the

\section{What is already known on this subject}

- Inequalities in health and mortality are shaped by experiences of advantage and disadvantage across the life course.

- Little is known regarding the efficacy of retirement income policies in supporting living standards and health among vulnerable adults.

- This study identified dominant trajectories of material living standards prior to and following eligibility for a universal age pension in New Zealand and describes the associated experiences of health. 


\section{What this study adds}

- A majority of older adults in New Zealand have good material living standards and maintain good health with age (86.1\%).

- A minority experience material hardship and display poor physical and mental health prior to age 65 .

- Mental health improves among those in material hardship whose living standards improve with age (8.8\%).

- Physical and mental health decline for those in hardship whose living standards do not improve in later life (5.1\%).

potential for significant differences in both the level and trajectory of living standards in later life under a universal pension system.

\section{Conclusions}

As populations live longer lives, expanding our knowledge about the material and non-material conditions associated with older age today will be important to understanding the diversity of needs, capacities and contributions of this large, increasing, and heterogeneous population. Current findings highlight that under current policy settings, a majority of older adults in New Zealand experience good living standards, physical and mental health in the decades prior to and following pension eligibility. However, smaller proportions of the population experience hardship in living standards, and poor health the decade prior to pensionable age. Current evidence suggests that increases in age of pension eligibility may disproportionately impact material and non-material well-being among disadvantaged adults.

\section{Twitter Joanne Allen @joallenNZ}

Contributors JA designed and conducted the empirical analysis and drafted the manuscript. FMA co-designed the longitudinal study, provided the data, contributed to data interpretation and revisions of the manuscript. All authors approved the final version.

Funding This research was prepared in response to a request for a background paper supporting the Commission For Financial Capability's 2019 Review of Retirement Income Policies. Health, Work and Retirement surveys 2006-2018 have been supported by the Health Research Council of New Zealand (grant number 05/311); the New Zealand Foundation for Research, Science and Technology (grant number MAUX0401); the New Zealand Ministry of Business, Innovation and Employment (grant numbers MAUX1205, MAUX1403, MAUX1705) and the EQC Biennial Grants Programme.

Disclaimer The views expressed in this paper do not necessarily represent those of the funders. Financial sponsors played no role in the design, execution, analysis and interpretation of data or writing of the study.

Competing interests None declared.

\section{Patient consent for publication Not required}

Ethics approval Data collection was approved by the Massey University Human Research Ethics Committee (SOA05/90, SOA09/17, SOB15/72, SOB09/70, SOB13/30, SOA15/72). Data linkage to National Mortality Records held by the Ministry of Health was approved by the Central Health and Disability Ethics Committee (18/CEN/69).

Provenance and peer review Not commissioned; externally peer reviewed.

Data availability statement Data are available on reasonable request. Statistical output supporting this research have been archived to the Open Science Framework (https://osf.io/xjcb2/?view_only=51f964e9795c4bc29a3b21c61f3f6364). Deidentified data from the Health, Work and Retirement study are available for purposes of health research by contacting the corresponding author or the Health and Ageing Research Team at hart@massey.ac.nz. Please contact the corresponding author for protocols regarding analyses that involve the use or interpretation of information related to Māori ethnicity.

Open access This is an open access article distributed in accordance with the Creative Commons Attribution Non Commercial (CC BY-NC 4.0) license, which permits others to distribute, remix, adapt, build upon this work non-commercially, and license their derivative works on different terms, provided the original work is properly cited, appropriate credit is given, any changes made indicated, and the use is non-commercial. See: http://creativecommons.org/licenses/by-nc/4.0/.

\section{ORCID iD}

Joanne Allen http://orcid.org/0000-0002-5003-8088

\section{REFERENCES}

1 Lawlor DA, Ebrahim S, Davey Smith G. Adverse socioeconomic position across the lifecourse increases coronary heart disease risk cumulatively: findings from the British women's heart and health study. J Epidemiol Community Health 2005; 59:785-93.

2 Majer IM, Nusselder WJ, Mackenbach JP, et al. Socioeconomic inequalities in life and health expectancies around official retirement age in 10 Western-European countries. J Epidemiol Community Health 2011;65:972-9.

3 Richardson T, Elliott $P$, Roberts $R$. The relationship between personal unsecured debt and mental and physical health: a systematic review and meta-analysis. Clin Psychol Rev 2013;33:1148-62.

4 Hamilton HA, Wickens CM, Ialomiteanu AR, et al. Debt stress, psychological distress and overall health among adults in Ontario. J Psychiatr Res 2019;111:89-95.

5 Fors S, Modin B, Koupil I, et al. Socioeconomic inequalities in circulatory and all-cause mortality after retirement: the impact of mid-life income and old-age pension. Evidence from the Uppsala birth cohort study. J Epidemiol Community Health 2012;66:e16.

6 Murray ET, Carr E, Zaninotto P, et al. Inequalities in time from stopping paid work to death: findings from the ONS longitudinal study, 2001-2011. J Epidemiol Community Health 2019;73:1101-7.

7 OECD. Preventing ageing unequally. Paris: OECD Publishing, 2017.

8 Butterworth P, Olesen SC, Leach LS. The role of hardship in the association between socio-economic position and depression. Aust N Z J Psychiatry 2012;46:364-73.

9 Benzeval M, Judge K. Income and health: the time dimension. Soc Sci Med 2001;52:1371-90.

10 Miething A, Åberg Yngwe M. Stability and variability in income position over time: exploring their role in self-rated health in Swedish survey data. BMC Public Health 2014;14:1300

11 OECD. Pensions at a glance 2017. OECD and G20 indicators. Paris: OECD Publishing, 2017.

12 Perry B. The material wellbeing of older New Zealanders: background paper for the Retirement Commissioner's 2013 review: Ministry for Social Development; 2013.

13 Krishnan, Jensen B. An overview of the living standards of the total population. In: New Zealand living standards 2000. Wellington: Centre for Social Research and Evaluation, Ministry of Social Development, 2002.

14 Perry B. The material wellbeing of new Zealand households: trends and relativities using non-income measures, with international comparisons. Wellington: Ministry of Social Development, 2018

15 Statistics New Zealand. Census QuickStats about people aged 65 and over. 2015 Wellington: New Zealand, 2013.

16 Allen J, Alpass FM, Stephens CV. New Zealand Health, Work and Retirement Longitudinal Study. In: Gu D, Dupre ME, eds. Encyclopedia of gerontology and population aging. Cham: Springer International Publishing, 2019: 1-7.

17 Jensen J, Spittal M, Krishnan V. ELSI short form: user manual for a direct measure of living standards. Wellington: Ministry of Social Development, 2005.

18 Jensen J, Krishnan V, Spittal M. New Zealand Living Standards: Their Measurement and Variation, with an Application To Policy. In: Social policy Journal of new Zealand, 2003: 72-97.

19 Ware J, Kosinski M, Turner-Bowker D, et al. How to score version 2 of the SF-12® health survey (with a supplement documenting version 1). Lincoln, Rl: Quality Metric Incorporated, 2002

20 Frieling MA, Davis WR, Chiang G. The SF-36v2 and SF-12v2 health surveys in New Zealand: norms, scoring coefficients and cross-country comparisons. Aust N Z J Public Health 2013:37:24-31.

21 Muthén LK, Muthén BO. Mplus User's Guide. 8th ED. Los Angeles, CA: Muthén \& Muthén, 1998-2017.

22 Atkinson J, Salmond C, Crampton P. NZDep2013 index of deprivation. Dunedin: University of Otago, 2014

23 Nylund KL, Asparouhov T, Muthén BO. Deciding on the number of classes in latent class analysis and growth mixture modeling: a Monte Carlo simulation study. Struct Equ Modeling 2007;14:535-69.

24 Muthén B. Latent Variable Analysis: Growth Mixture Modeling and Related Techniques for Longitudinal Data. In: Kaplan D, ed. The SAGE Handbook of quantitative methodology for the social sciences. SAGE Publications, 2004.

25 Clark S, Muthén B. Relating latent class analysis results to variables not included in the analysis 2009.

26 Vermunt JK. Latent class modeling with covariates: two improved three-step approaches. Political Analysis 2010;18:450-69. 
27 Butterworth P, Rodgers B, Windsor TD. Financial hardship, socio-economic position and depression: results from the path through life survey. Soc Sci Med 2009;69:229-37.

28 Mansvelt J, Breheny M, Stephens C. Pursuing security: economic resources and the ontological security of older new Zealanders. Ageing Soc 2014;34:1666-87.
29 Topa G, Depolo M, Alcover C-M. Early retirement: a meta-analysis of its antecedent and subsequent correlates. Front Psychol 2018;8.

30 Di Gessa G, Corna LM, Platts LG, et al. Is being in paid work beyond state pension age beneficial for health? Evidence from England using a life-course approach. $J$ Epidemiol Community Health 2017;71:431-8. 